\title{
OPINIÃO PÚBLICA, DEMOCRACIA E ELEIÇÕES: O QUARTO PODER EM TEMPOS DE REDES SOCIAIS
}

\author{
Wallace Moacir Paiva Lima ${ }^{1}$
}

RESUMO: Os tempos já não são os mesmos, a pós-modernidade trouxe o avanço tecnológico proporcionado pela $4^{-}$Revolução Industrial também chamada de indústria 4.0, conectando todos os lugares, locais e pessoas com simples toque. As redes sociais, que inicialmente surgiram com Orkut, hoje fazem parte do dia a dia, as pessoas não acordam e vão comprar seus jornais, elas acessam a internet e logo chegam a elas, as notícias, verdadeiras ou não, ética ou nem tanto. Qualquer um pode promover uma publicação, disseminar fatos ou fake News., com uma mídia talvez mais voltada à esquerda como ideologia política e com imparcialidade nem sempre notável os últimos anos marcaram um declínio da credibilidade da mídia tradicional no Brasil. Diante do exposto esse estudo trata de um ensaio sobre a imprensa brasileira em termos de redes sociais, buscou-se verificar a evolução do jornalismo, o nascimento das fakes News e discutir as mídias digitais.

Palavras-Chave: Eleição. Imprensa. Mídias Digitais. Redes Sociais.

\section{INTRODUÇÃO}

Desde a segunda metade do século XX, muito já se produziu em termos acadêmicos no que se refere ao comportamento eleitoral e suas possíveis motivações. Algumas hipóteses podem ser sugeridas enquanto fatores que moldariam as preferências: a primeira delas é o personalismo, ou aquelas qualidades atribuídas ao candidato como carisma, honestidade, "ser trabalhador", "ser competente" etc.; a segunda é o poderio econômico, isto é, o candidato que usufrui de uma dada estrutura de campanha (e administra bem esses recursos) irá se sobressair em relação aos outros concorrentes; em terceiro lugar está a ideia da ligação (e vantagens) do candidato ao campo político do Governo do Estado.

\footnotetext{
1 Formação Acadêmica: Ciências Políticas e Relações Internacionais pelo Centro Universitário Internacional do Paraná (UNINTER).E-mail:negrini.agnes@gmail.com.
} 
Nas últimas eleições um novo elemento surgiu: o das fakes News como método de impulsionar candidato. Para fins desse estudo não se defende estratégias utilizadas por determinado partido, trata-se de um estudo sobre a credibilidade da imprensa em tempos de redes sociais e, sobretudo, sua influência no processo eleitoral de hoje, de ontem e do amanhã.

A sociedade, como um todo, é envolvida em um processo contínuo de passagem entre o tradicional e o inovador. A sensação eminente nas narrativas científicas é a de que um modelo velho dá espaço a um novo, e, assim, vão sendo substituídos conceitos, formas de vida, linguagem, estilos de gestão, marketing, marcas etc.

Sabe-se, ainda, que as novas formas de agir, de pensar e de se comportar são produções resultantes da interação de diversos componentes que constituem o espírito do tempo presente. Essa interpretação pode ser claramente observada na perspectiva do Zeitgeist ${ }^{2}$ definido pelo filósofo Hegel. Em meio a essa transição e impactadas por esse movimento, estão a vida familiar e a vida profissional, a falta de identidade, a vida engolida pelas redes sociais.

Nessa perspectiva, o contexto capitalista e globalizado que envolve a sociedade pósmoderna gera implicações em todas as suas concepções fundamentadoras, nas quais se encontram as famílias e as organizações e ambos com um problema em comum: a falta de identidade. Todo processo demanda adaptações amplas e, às vezes, imediatas. A leitura que este estudo pretende direcionar aos aspectos das vidas familiar e profissional, em empresas nascentes em estruturas familiares, está amparada na proposta de compreensão dessas dimensões com base no olhar sobre os sistemas familiar e empresarial e suas interações.

A internet alterou a forma de relacionamento entre as pessoas, as empresas e o governo, de forma a criar uma espécie de comunidade global interativa, que veio alterar ao mesmo tempo uma série de paradigmas, rompendo com as fronteiras geográficas, abalando culturas, causando impacto na economia etc.

\footnotetext{
${ }^{2} \mathrm{O}$ Zeitgeist significa, em suma, o conjunto do clima intelectual e cultural do mundo, numa certa época, ou as características genéricas de um determinado período.
} 
Justifica-se a importância desta pesquisa pela fundamental relevância desta temática no âmbito da ciência política e jornalística contemporânea, especialmente porque tentará suprir uma lacuna de estudos sobre comportamento eleitoral.

Acredita-se que a imprensa precisa adotar princípios da transparência, do comportamento ético e se adequar ao novo consumidor de seu produto, aquele que acessa as redes sociais e é constantemente "bombardeado" de notícias falsas e/ou verdadeiras.

\section{A ESTRUTURA POLÍTICA}

Para Gomes (2004) a política funciona sempre com base em práticas, habilitações, classes de agentes e representações interrelacionados e reciprocamente implicados de forma sistêmica. Na verdade, formam-se à base da política verdadeiros sistemas de práticas, de habilitações etc. que funcionam como instâncias objetivas que orientam a ação, estruturam os comportamentos $\mathrm{e}$ as disposições, administram as recompensas $\mathrm{e}$ as punições, determinam metas e parâmetros, controlam a admissão e a exclusão. O autor completa que:

Cada sistema é uma forma singular, um peculiar repertório de configuração de regras de comportamento, de padrões de atitudes e de interação, de formatação de interesses, de conhecimentos práticos, de valores e significados, de papéis e de princípios que valem no campo político nesse momento e nesse lugar. Em sociedades complexas, a atividade política se apoia em mais de um desses sistemas, de forma que quando um deles é substituído ou alterado, o campo político e a atividade política de tais sociedades não cessam nem desaparecem. Nem mesmo se pode depreender - pelo menos não com força de necessidade - da mudança de um dos sistemas o fato de que a política que nessa sociedade se pratica tenha mudado globalmente. Por outro lado, é evidente que a alteração num dos sistemas (de práticas, habilitações, agentes e representações) da política de algum modo altere a têmpera geral, a combinação que configura o todo (GOMES, 2004, p. 13).

Por sua vez, Liedtke (2007) admite que há um poder dos meios de comunicação de massa em interferir no repertório da comunicação interpessoal, com uma tendência de as pessoas conversarem e pensarem sobre os temas ofertados pela mídia. $\mathrm{O}$ autor completa:

A importância dos meios de comunicação de massa (MCM) reside no fato de mediar os acontecimentos gerados no governo federal, com possíveis consequências para a população e principalmente para o próprio Estado brasileiro. Entendemos que estes efeitos também serão perceptíveis no governo, que 
reconhecendo esse potencial da mídia, também tentará interferir no processo, disputando espaços no campo jornalístico (LIEDTKE, 2007, p. 8).

Nesse sentido, diante da experiência negativa passada, os indivíduos passam a temer o futuro, e por isso, rejeitam a possibilidade de nova experiência. Portanto, sentir medo é temer um futuro perigoso, incerto. Tem-se a premissa, portanto, de que eleitores rejeitam, ou melhor, sentem medo de candidatos à presidência da República. Assim sendo, eleitores podem temer a reeleição do presidente ou a vitória da oposição. Se eleitores temem a reeleição do presidente, eles expressam receio quanto ao futuro em razão da experiência negativa com o presidente atual. Porém, caso eles expressem medo diante do sucesso eleitoral da oposição, ficam incertos quanto ao que virá, por exemplo, temem a perda de conquistas adquiridas no período do presidente não reeleito.

Carreirão (2002), assim como Marques e Miola (2018) e Camargo (2001), concordam que desde o início desse século os eleitores decidem os votos de acordo com o ponto de vista emocional, baseado na imagem dos candidatos, incluindo o caráter e a moral. É nesse contexto que se explica o peso do carisma do candidato em uma campanha. Muitos

eleitores identificam-se com o político e esse fator deve ser levado em conta para a verificação do comportamento eleitoral. Carreirão (2002, p.34) destaca que este novo eleitor “tem baixa informação e saber político; suas ideias políticas são fragmentárias e logicamente desarticuladas, daí porque ele é incoerente do ponto de vista político e volúvel eleitoralmente".

Por sua vez, a teoria sociológica do comportamento eleitoral se baseia nas características sociais e culturais do eleitor, e, para isso leva em consideração suas origens e seu modo de viver e se relacionar. De acordo com Santos (2010, p. 12), a teoria sociológica é mais abrangente que a psicológica "uma vez que engloba o contexto social, histórico e cultural do eleitor e não apenas o individualismo como o gerador de suas atitudes". A teoria sociológica leva em consideração vários aspectos, conforme já visto, dentre eles destacam-se as interações sociais e a identidade cultural, porém, outro aspecto levado em consideração e tendo grande importância é a questão das classes sociais.

Recentemente, os sentimentos e as emoções dos eleitores foram incluídos no rol de variáveis que podem também explicar o comportamento dos eleitores. Assim como o local 
de moradia do eleitor, índice de desemprego e homicídio ou aumento das passagens de ônibus (OLIVEIRA, 20I2). Contudo, como bem mostra a literatura brasileira, os hábitos dos indivíduos ainda não foram considerados como variáveis que podem explicar seu comportamento na hora do voto.

A última corrente que tenta explicar o comportamento eleitoral é a da escolha racional. Esta teoria, segundo Santos (2010, p. 20):

\begin{abstract}
(...) explica a decisão do voto levando em consideração o interesse individual do eleitor, que opta pelo candidato que ele acredita que lhe trará mais benefícios pessoais. O eleitor agiria como um juiz que decide se o político merece permanecer representando-o ou precisa ser trocado por outro, que lhe garanta melhores expectativas. A maioria absoluta dos estudos sobre comportamento eleitoral realizados no Brasil é pautada pela teoria da escolha racional.
\end{abstract}

Camargo (200I) esclarece que, os principais intelectuais da teoria da escolha racional são Antony Downs e V. O. Key Jr. Segundo o autor, Key foi um dos fundadores dessa corrente e suas investigações seguem a linha chamada de recompensa punição. Por sua vez, Carreirão (2002) esclarece que, na concepção de Key, o eleitor avalia e julga os resultados em geral do governo e não as políticas/meios adotados. Portanto, em sua tomada de decisão, a pessoa analisa a performance dos candidatos e não compara as propostas. Essa, para o autor, seja a principal diferença entre as linhas de investigação de Key e Downs, uma vez que este, de acordo com Carreirão (2002), observa que o resultado das eleições pode estar muito mais relacionado às políticas adotadas do que com o resultado delas. Assim sendo, pode-se dividir a teoria da escolha racional em duas outras linhas: voto retrospectivo (quando o eleitor examina as ações passadas do candidato) e o voto prospectivo (quando o eleitor avalia as propostas de atuação futura do candidato).

Camargo (200I) ao realizar uma análise da decisão dos eleitores durante a eleição presidencial de 1998 no Brasil, disputada por Fernando Henrique Cardoso (PSDB), candidato à reeleição, e Luiz Inácio Lula da Silva (PT). O pleito foi vencido pelo primeiro e, para o autor, as questões econômicas daquele momento foram determinantes para esse resultado. Segundo o autor, a diferença entre a perspectiva pessoal e sociotrópica ${ }^{3}$ está na

${ }^{3}$ É a valorização das relações interpessoais íntimas e é dependente de gratificações sociais, com ênfase em ser aceito e amado pelos outros, o segundo caracteriza-se pela personalidade autônoma, independência pessoal, obtém satisfação na liberdade de escolha, conquistas e aquisição pessoal. 
observação geral do contexto econômico. Eleitores mais envolvidos com a política estariam também preocupados com questões que vão além do seu interesse particular.

\begin{abstract}
Nossos dados demonstram que, no Brasil, em 1998, o peso das avaliações prospectivas foi maior do que o das retrospectivas, ou seja, o eleitor brasileiro, na hora do voto, está mais preocupado com o futuro do que com o passado. Além disso, exercem um impacto maior no voto de ambos os candidatos as variáveis de avaliação que o eleitor faz da situação nacional, e não as de avaliação da própria situação, sugerindo, com isso, que o eleitor brasileiro é menos preocupado com o próprio bolso do que o eleitor americano. (CAMARGO, 200I, I44)
\end{abstract}

Analisando a eleição presidencial de 1998, CAMARGO (200ı) conclui que "o eleitor brasileiro decide a direção do seu voto olhando para o passado e construindo futuros possíveis caso um ou outro candidato vença a eleição" (CAMARGO, 200I, I43). Não se pode negar a importância das questões econômicas quando da avaliação para a decisão do voto, como defende a teoria da escolha racional. Embora bastante abrangente e com análises consistentes acerca do comportamento eleitoral durante uma eleição, a corrente da escolha racional deixa de lado questões que, como já apontado nos capítulos anteriores, também influenciam na direção do voto, como identificação ideológica e partidária , condições sociais e culturais e o envolvimento do eleitor com entidades de classe (THOMPSON, 2000).

Dialogando com Santos, enfatizamos que para Gomes e Maia (2008) o interesse por política varia de pessoa para pessoa e as atitudes do eleitor frente a ela é o ingrediente básico para se compreender determinado tipo de comportamento eleitoral. Conforme essa corrente, o ato de votar é resultado de forças atitudinais. A análise que o eleitor faz sobre ir ou não às urnas, participar ou não participar ativamente da política, também poderia ser explicada pela teoria psicológica.

\title{
MÍDIA E POLIITICA: O SUCESSO DAS FAKES NEWS
}

Quando retomamos ao começo do século XIX, já pontuamos a mudança - o jornalismo no qual era possível se colocar, tornou-se um jornalismo, onde a informação era tida como foco principal. Outras transformações surgiram com a meta de arrecadação 
financeira em sua amplitude, com o desenvolvimento urbano e industrial, permitindo um senso crítico em suas opiniões em seus modos de agir, pensar, interpretar etc.

O que se torna notícia precisa ter veracidade nas informações por quem as transmite formalmente. No meio do jornalismo, o costume é de que eles atuam como pessoas jurídicas, sem um relacionamento problemático ou dificultoso, totalizando em um trabalho de sucesso.

Agrega-se aqui, a mudança para a demonstração do que de fato sentimos, evidenciando mais questionamentos, confiança e o uso do espelho gatekeeper, ação, interação e construção com toda uma autenticidade de um jornal.

Uma crise (no jornalismo) é capaz de se ampliar pela tecnologia em países como o Brasil. É destaque hoje um efeito: As Fake News, embora não sejam mais atuais, ainda são uma influência na mídia digital e geram:

O declínio de notícias como legado; maior necessidade de imediatismo no processo de produção de notícias; a rápida circulação de informação enganosa e desinformação via produtores de conteúdo e anunciantes; o aumento do discurso emocional no ambiente on-line; o grande número de pessoas capitalizando financeiramente algoritmos usados por plataformas de redes sociais e mecanismos de busca na Internet; plataformas como Facebook, WhatsApp são em algumas vezes divulgadoras de notícias inverídicas, gerando questionamentos, mas que no final têm uma resposta óbvia : a verificação das informações (VINCIPROVA, 2019, p.492)

O sucesso das Fake News pode ser justificado pela falta de confiança nas instituições políticas e jornalísticas. Em se tratando das instituições políticas, Gomes (2010, p. 29) afirma:

A literatura associa a desconfiança política à reprovação ao desempenho dos atores políticos, formada a partir de denúncias de malversação e de corrupção amplamente divulgadas pela mídia. A pesquisa objeto deste artigo também evidenciou que a confiança nas instituições e nos atores políticos tende a responder a uma avaliação de desempenho das mesmas, e estas costumam repercutir as informações veiculadas pela mídia, embora com intensidade diversa dependendo dos veículos, das segmentações e do grau de sofisticação intelectual necessária para compreendê-las.

Diante do quadro das Fake News, surge também a necessidade de transparência ou e-transparência que segundo Almada, Gomes e Amorim (2018, p. 5),

Aparentemente, isso significa muito pouco, vez que as práticas e comportamentos humanos são principalmente analógicos, mas, em um mundo em acelerada 
digitalização e hiperconectado, em pouco tempo não fará mais sentido distinguir entre transparência off-line e e-Transparência.

O que se percebe com a leitura do artigo de Almada, Gomes e Amorim (2018) é que um projeto de e-transparência pode combater fake News utilizando os mesmos artefatos, ou seja, projetos e iniciativas de natureza digital, assim como, de bancos de dados informatizados que possam produzir mais e melhor transparência em governos, instituições e organizações.

O ponto de partido para uma possível solução para esse quadro se basearia no conceito de Blumler e Coleman (2007) de comunicação cívica, que surge em um cenário democrático e de vivência da democracia.

Como a própria democracia, todos esses propósitos de comunicação cívica são concebíveis como ideais, que podem ser realizados em maior ou menor grau. No entanto, eles terão uma chance muito maior de serem realizados em sociedades com comunicação e políticas econômicas e sociais igualitárias (BLUMLER e COLEMAN, 2007, p. 12).

Ou seja, todos os atores políticos - políticos, jornalistas, comentaristas e cidadãos (mesmo acadêmicos!) podem errar em suas seleções e interpretações de informações e em suas ideias de avanço e mudança política. Outro aspecto é o respeito pela diferença como característica incorporada da condição humana, refletida nos variados objetivos de vida que as pessoas possuem, os modos de vida que eles podem valorizar e desfrutar, e as formas de pensar sobre o mundo ao seu redor e em como entretê-lo (MIGUEL e BIROLI, 2009). Um terceiro aspecto requer ainda uma apreciação sutil e complexa da interconectividade das coisas. Isso significa dizer que questões políticas, problemas e condições devem sempre ser considerados dentro de um panorama maior, e não como especificações isoladas, mas em contextos mais amplos, muitas vezes com contrapartidas no que diz respeito à política.

\section{CONCLUSÃO}

O ambiente eleitoral da última eleição para presidente, governadores, deputados e senadores foi marcada por uma nova forma circular informações, as chamadas fakes News. A atualidade não antecipa sequer a força do mundo da Internet e sim uma sugestão na 
prática jornalística, proporcionando um índice de profissionais ainda mais elevado hoje em dia, e de um grupo de pessoas com um poder com um poder maior de questionamento, tornando-se mais atuantes, o que anteriormente, não havia a probabilidade de acontecer.

Esses fatos levam a critérios, a resultados (positivos), porém, acabamos por fugir da argumentação e da verdadeira realidade, uma conversa participativa onde o foco, é a opinião do indivíduo.

Concluindo este ensaio torna-se importante recapitular os seguinte pontos de fundamental importância para esse artigo: I) a decisão do eleitor em quem votar, essa é uma escolha bastante complexa, como bem mostram as tentativas de explicá-la, apontadas nesse item; 2) constatação de que cada uma das três correntes tradicionais (psicológica, sociológica e da escolha racional) tem um foco próprio de análise do comportamento do eleitor; 3) a evidencia da teoria sociológica que explica o voto a partir da interação social, por exemplo, a participação do eleitor em grupos específicos, dialoga com a teoria psicológica que mostra que a decisão por um candidato é vista como resultado da ideologia; e, 4) pôr fim, a teoria da escolha racional, que o voto depende da atuação econômica do governo paralelamente aos benefícios financeiros que o eleitor teve ou terá com determinado candidato.

Os eleitores estão inseridos no ambiente social. Eles têm visões de mundo, desejos e hábitos. As visões de mundo dos eleitores são representadas por suas crenças e valores. Os eleitores expõem demandas para os competidores. O hábito é a prática rotineira. Visões de mundo, desejos e hábitos podem de decifrar as escolhas dos eleitores em uma ou em várias eleições. O reconhecimento de que as visões de mundo dos eleitores têm o poder de explicar as suas escolhas, revela que os neodeterminantes do voto podem surgir.

As lógicas ou conclusões apresentadas acima soam como antirrepublicanas. Mas são democráticas. Pois, o eleitor, ao ter o direito de votar, expõe os seus desejos reais. Entretanto, por não ser republicana, a democracia ideal é ferida. Tal tipo de democracia caracteriza-se pelo desejo do eleitor em ser defensor de práticas republicanas, condenar ilicitudes dos políticos e defender, intransigentemente, o bem comum. Contudo, não é isso, necessariamente, que as pesquisas de opinião pública revelam. Por outro lado, bons gestores são premiados pelos eleitores. Investir em saúde e segurança pública contribui 
para a reeleição de prefeitos. Neste caso específico, observo o eleitor republicano, pois este respalda os gestores que promovem o bem comum; e, claro, atende as suas necessidades. Existem, portanto, eleitores republicanos, antirrepublicanos e híbridos (republicanos e antirrepublicanos concomitantemente).

\section{REFERÊNCIAS}

ALMADA, M. P.; GOMES, W. S.; Amorim, P. K. D. F. Novos desafios para a ideia de transparência pública. E-COMPÓS (BRASÍLIA), p. I-2I, 2018.

BLUMler, J.; COLEMAN, S. A democracia e a mídia - Revisitadas. Compolítica, v. 7, n. 2, p. 7-34, I8 nov. 2017.

CARREIRÃO, Yan de Souza. A eleição presidencial de 2002: uma análise preliminar do processo e dos resultados eleitorais. Revista de Sociologia e Política, Curitiba, n. 22, p. I79I94, jun. 2004.

COLEMAN, S. O agir democrático numa era de redes digitais. Compolítica, v. 7, n. I, p. 7-26 [27, 28 jun. 2017.

GOMES, Wilson. Transformações da Política na Era de Comunicação de Massa. São Paulo: Edit. Paulus, 2004.

LIEDTKE, P. Governando com a mídia: o agendamento mútuo entre o Estado e os mass media na política nacional. In: Encontro da Compós,, I4., Curitiba. Anais... Curitiba, 2007

MARQUES, F. P. J. A.; MIOLA, Edna. 1989, o ano que não terminou: epistemologia e metodologia da pesquisa em Comunicação e Política no Brasil. Comunicação \& Sociedade, v. 33, p. 107, 2018.

MIGUEL, L. F.; BIROLI, F. A Produção da Imparcialidade: a construção do discurso universal a partir da perspectiva jornalística. In: Encontro da Compós, 28, Belo Horizonte. Anais... Belo Horizonte, 2009.

OLIVEIRA, A. O estado da arte dos determinantes do voto no Brasil e as lacunas existentes. Sociedade E Cultura, $15(\mathrm{I}), 2012$

RODRIGUES, M. R. O papel da imprensa na qualidade democrática - Uma análise de possibilidades nos principais jornais nacionais. Tese de doutorado defendida pelo Iesp- 
Uerj em janeiro de 20II. Disponível em: http://www.iesp.uerj.br/tesesonline/ciencia\%2opolitica/2010/Malena\%2oRehbein\%2oRodrigues.pdf

RODRIGUES, M. R. Imprensa e Congresso ou Como a mídia pauta a política. Brasília: Câmara dos Deputados, 2002. -> Artigo referente ao livro: RODRIGUES, Malena Rehbein. Do Agenda Setting ao Congresso Nacional: um processo de muitas vias. In: Intercom - Sociedade Brasileira de Estudos Interdisciplinares da Comunicação, 2002. Disponível em: http://www.intercom.org.br/papers/xxi-ci/qto3/qto304.pdf

SANTOS, Edilene dos. Decisão do voto: um debate sobre as teorias do comportamento eleitoral. Monografia apresentada ao Curso de Pós-graduação lato sensu Comunicação Política e Imagem, Turma II, como requisito parcial à obtenção do grau de especialista. Curitiba, 2010.

THOMPSON, J.B. O Escândalo Político: Poder e Visibilidade na era da mídia. Rio de Janeiro: Editora Vozes, 2000. 